\title{
DELÍRIOS I - AGONIA E EXPERIÊNCIA (JOGOS DE VIDA E MORTE)
}

\author{
Vinícius Nicastro Honesko \\ Doutorando do Curso de Pós-Graduação em Literatura - UFSC
}

\begin{abstract}
RESUMO
O presente ensaio pretende expor uma ideia de agonia como jogo de vida e morte no qual imerge o artista no ato de criação. A partir das leituras e conceituações do termo jogo em Johan Huizinga e em Roger Caillois, mostra como tais ideias são importantes para compreender a experiência humana diante do incompreensível que é a morte. Aponta como a agonia inspira no poeta, principalmente na modernidade, uma distância em relação às certezas do conhecimento, implicando uma leitura etimológica do termo experiência, isto é, como ex periri, (aqui, também, jogo de vida e morte). Por fim, procura ver como os traços desse jogo uma eterna luta - sutilmente se mostram nos pânicos de Murilo Mendes e de Paul Gauguin, artistas nos quais a consciência dessa luta é atravessada pela imagem do lugar por excelência da agonia: o Calvário.
\end{abstract}

\section{PALAVRAS-CHAVE}

Agonia; Jogo; Experiência; Jogo de vida e morte; Calvário.

\section{DELUSIONS I - AGONY AND EXPERIENCE (GAMES OF LIFE AND DEATH)}

\begin{abstract}
The present essay intends to expose an idea of agony as a life and death game in which the artist immerses himself in the act of creation. From the readings and conceptions of the term game in Johan Huizinga and in Roger Caillois, it exposes how such ideas are important to comprehend the human experience before the incomprehensible that is death. It shows how agony inspires the poet, principally in modernity, a distance from the certitudes of knowledge, implying an etymological reading of the term experience, that is, as ex periri (here, also, life and death game). Finally, it tries to see how the traces of this game - an eternal fight - subtly show themselves in the panics of Murilo Mendes and Paul Gauguin, artists in which the conscience of this fight is pervaded by the image of the place by excellence of agony: the Calvary
\end{abstract}

\section{KEYWORDS}

Agony, game; Experience; Life and death game; Calvary. 
Johan Huizinga, em seu Homo Ludens, nos traz um plexo interessante a partir do qual traça sua concepção de jogo. Num itinerário que tem início com a compreensão do jogo enquanto fenômeno cultural, passando por análises condizentes às possíveis relações entre o jogo e o direito, a guerra, o conhecimento e a poesia, o autor expressa sua ideia de jogo de maneira a colocá-lo como elemento primordial da civilização (isto é, de toda civilização humana). No entanto, logo no segundo capítulo do livro, no qual discutirá a noção de jogo e sua expressão na linguagem, Huizinga se depara com um problema crucial na suas diferenciações conceituais. Quando analisa a terminologia grega para o termo, o autor sugere que, além da desinência -inda (específica para jogos infantis) e dos termos atrelados aos sintagmas paidia e atúrou, há também uma esfera semântica muito ampla e importante para a categorização do jogo: trata-se do termo agon, isto é, todo o domínio das competições e concursos (HUIZINGA, 2007, p. 35). De fato, Huizinga tem consciência da ampliação da ideia de jogo quando do uso do agon e, inclusive, chama a atenção para as críticas que lhe foram feitas pelo fato da inclusão de agon na esfera do jogo.

Todo este domínio, de tão grande importância para a vida dos gregos, é designado pela palavra agon. Pode-se bem dizer que no terreno do agon está ausente uma parte essencial do conceito de jogo. Ao mesmo tempo, devemos admitir que os gregos podiam ter muita razão em estabelecer uma distinção lingüística entre a competição e o jogo. É certo que regra geral o elemento de "nãoseriedade", o fator lúdico propriamente dito, não é claramente expresso pela palavra agon. Além do mais, as competições de todo o gênero desempenhavam um papel de tal modo importante na cultura grega e na vida quotidiana de todos os gregos que pode parecer excessiva ousadia a pretensão de classificar como "jogo" uma parte tão grande da civilização grega (IDEM).

Contrariando seus críticos, para os quais agon seria mais nobre do que o jogo, Huizinga entende que essas esferas são conexas. Isto é, ao jogo, uma vez comportando em seu sentido também o agon, estariam adstritas grandes e importantes searas da vida grega como um todo, quais sejam, as competições e concursos. Ousando uma classificação de jogo que justamente inclua um atrelamento com agon, ele pretende ampliar sua esfera em direção a uma compreensão que a atrele de modo irresoluto à própria ideia de civilização. $\mathrm{O}$ jogo - e talvez seja essa a proposta central do livro - cumpriria, em seu caráter competitivo, o papel de operador "civilizacional" dos agrupamentos humanos; ele seria, em certo aspecto, uma espécie de modulador 
antropogenético, uma máquina de produção de "cultura humana". Assim continua Huizinga na sua argumentação:

O agon na vida dos gregos, ou a competição em qualquer outra parte do mundo, possui todas as características formais do jogo e, quanto à sua função, pertence quase inteiramente ao domínio da festa, isto é, ao domínio lúdico. É totalmente impossível separar a competição, como função cultural, do complexo "jogo-festa-ritual" (IDEM. p. 36).

A função cultural do evento competitivo, sua feição ritual - sempre realçada pelas interpretações antropológicas como aquilo que possibilita, de certo modo, a formatação de uma cultura particular, bem como a própria formação da cultura humana (em oposição a um suposto elemento natural) - permanece, segundo Huizinga, sempre atrelada às concepções de festa e jogo.

As razões devido às quais a língua grega estabelece essa nítida distinção terminológica entre o jogo e a competição podem, em minha opinião, ser explicadas da seguinte maneira. A concepção de uma noção geral de jogo, universal e logicamente homogênea, é, como vimos, uma invenção lingüística bastante tardia. Todavia, desde muito cedo as competições sagradas e profanas haviam tomado um lugar tão importante na vida dos gregos, adquirido um valor tão excepcional, que as pessoas deixaram de ter consciência de seu caráter lúdico. Sob todos os seus aspectos e em todas as ocasiões, a competição tornara-se uma função cultural tão intensa que os gregos a consideravam perfeitamente "habitual", como algo que existia naturalmente. Foi por este motivo que os gregos, possuindo duas palavras distintas para designar o jogo e a competição, não conseguiram identificar de maneira clara a presença, no segundo, do elemento lúdico essencial, daí resultando que a união conceptual e, portanto, lingüística, entre ambas, nunca foi efetivamente realizada (IDEM. pp. 36-37).

A justificativa para a existência de esferas semânticas diversas para o jogo em geral e para a competição em particular trazidas aqui por Huizinga não elide, segundo o autor, uma equiparação (com as devidas precauções) das esferas, ou ainda, uma espécie de inclusão da esfera da competição dentro daquela que the é mais ampla, qual seja, a do jogo em geral. A questão da inclusão do grego agon como uma categoria de jogo seria, portanto, também um problema de conformação da linguagem. Porém, essa questão linguística levantada pela oposição dicotômica entre jogo/seriedade (lúdico/competitivo) não seria definitiva; ou melhor, trata-se sim de 
um problema linguístico, entretanto, fundamentalmente atrelado à questão, levantada por Lévi-Strauss, do excedente de significantes em relação aos significados (LÉVISTRAUSS, 1974, p. 73). ${ }^{1}$

Em certo sentido, a seara agonística, relativa às competições e concursos, não poderia deixar de ser integrada ao jogo por sua característica de seriedade. De fato, Huizinga lembra que jogo e seriedade não são categorias oponíveis e definíveis simetricamente, como se jogo tivesse um valor positivo e seriedade um valor negativo.

O significado de "seriedade" é definido de maneira exaustiva pela negação de "jogo" - seriedade significando ausência de jogo ou brincadeira e nada mais. Por outro lado, o significado de "jogo" de modo algum se define ou se esgota se considerado simplesmente como ausência de seriedade. O jogo é uma entidade autônoma. $\mathrm{O}$ conceito de jogo enquanto tal é de ordem mais elevada do que o de seriedade. Porque a seriedade procura excluir o jogo, ao passo que o jogo pode muito bem incluir a seriedade (HUIZINGA, 2007, p. 51).

Pari passu a essa leitura de Huizinga, podemos dizer que, nesse aspecto, jogo adquire a feição própria daqueles termos (que, em geral, acabaram por ser "descobertos" pela antropologia e ciências sociais de fins de século XIX e começo de século XX) que comportam uma ambiguidade constitutiva, um excedente de significação, tais com sacer, mana etc. Isto é, o jogo está além de sua simples pronúncia e categorização (como se um elenco de atividades - quase elevado ao infinito - pudesse dar conta das ações que compendiariam o ato ou efeito de jogar); ou melhor, está numa posição capaz de exibir o vazio de sentidos próprio à linguagem humana, o vazio que está na desconexão entre os nomes e as coisas.

\footnotetext{
${ }^{1}$ No belo trecho do ensaio de abertura das obras de Marcel Mauss, Lévi-Strauss arma o que talvez seja o cerne de toda sua antropologia. Aqui ele mostra como a compreensão da abertura entre significantes e significados, de certo modo, do hiato entre conhecer e significar, pode ser uma chave para a compreensão das diferenças culturais, bem como da compreensão do chamado desenvolvimento humano. O excerto é o que segue: "No momento em que todo o Universo, de um só golpe, tornou-se significativo, não tornou-se por isso mais bem conhecido, mesmo se for verdade que o aparecimento da linguagem devia precipitar o ritmo do desenvolvimento do conhecimento. Há, pois, uma oposição fundamental, na história do espírito humano, entre o simbolismo, que oferece um caráter de descontinuidade, e o conhecimento, marcado pela continuidade. Que resulta disso? Resulta que as duas categorias do significante e do significado constituiram-se simultânea e solidariamente, como dois blocos complementares; mas que o conhecimento, isto é, o processo intelectual que permite identificar, uns por relação com os outros, certos aspectos do significante e certos aspectos do significado (...) só marchou muito lentamente. (...) O universo significou muito antes de que se começasse a saber o que ele significava - isto é óbvio."
} 
É desse modo que podemos ver os redimensionamentos propostos às análises de Huizinga por toda uma série de autores que, ao lerem Homo Ludens, acabaram botando à prova as análises ali contidas.

Quando o sociólogo Roger Caillois, retomando Huizinga numa lógica muito mais propositiva, trata de - como the era comum estilisticamente - aprimorar diferenciações entre esferas de jogos de modo a apresentar um quadro tecnicamente delineado daquilo que chama modalidades de jogos, é justamente para tentar (como seria de praxe para o seu milieu) uma melhor escansão do conceito jogo. Assim, em seu Os Jogos e os Homens, Caillois traça o que para ele seriam as categorias fundamentais nas quais poderia ser dividido o conceito de jogo: agon, alea, mimicry e ilinx (CAILLOIS, 1986, pp. 43-64). O que aqui nos interessa, mais do que a ousadia de Caillois em tentar esmiuçar o problema do jogo, é sua explicação para a subcategoria agon.

Agon. Todo um grupo de jogos aparece como competência, isto é, como uma luta em que a igualdade de oportunidades se cria artificialmente para que os antagonistas se enfrentem em condições ideais, com possibilidade de dar um valor preciso e indiscutível ao triunfo do vencedor. Portanto, sempre se trata de uma rivalidade ao redor de uma só qualidade (rapidez, resistência, vigor, memória, habilidade, engenho etc.), que se exerce dentro de limites definidos e sem nenhuma ajuda exterior, de tal modo que o ganhador apareça como o melhor em certa categoria de proezas. Essa é a regra das competências desportivas e a razão de ser de suas múltiplas subdivisões, seja a oposição de dois indivíduos ou de duas equipes (pólo, tênis, futebol, boxe, esgrima etc.), seja a disputa entre um número indeterminado de concorrentes (corridas de toda espécie, competições de tiro, de golfe, atletismo etc.). À mesma classe pertencem também os jogos em que os adversários dispõem a princípio de elementos exatamente do mesmo valor e no mesmo número. O jogo de damas, de xadrez, de bilhar, são exemplos perfeitos. A busca da igualdade de oportunidades ao principiar constitui de maneira tão manifesta o princípio essencial da rivalidade que é restabelecida por meio de uma vantagem entre os jogadores de forças diferentes, isto é, que dentro da igualdade de oportunidades estabelecida num princípio, prepara-se uma desigualdade secundária, proporcional à força relativa suposta nos participantes. É significativo que esse uso exista tanto para o agon de caráter muscular (os encontros desportivos), como para o agon de tipo mais cerebral (as partidas de xadrez, por exemplo, nas que se dá ao jogador mais fraco a vantagem de um peão, de um cavalo ou de uma torre) (IDEM. pp. 43-44). ${ }^{2}$

\footnotetext{
${ }^{2}$ Toda citação em outra língua que não o português foi traduzida no corpo do texto e mantida no original em nota de rodapé. "Agon. Todo um grupo de juegos aparece como competencia,
} 
A categorização do agon esboçada por Caillois - em certo sentido um alongamento da empreendida por Huizinga - marca exatamente a forma competitiva do jogo agon; a disputa, a luta, a exaustão suposta pela competição nos fazem perceber a tensão de que está prenhe toda agonia, toda aposta na vitória diante de um adversário. Agon, a luta pela vitória em jogo no jogo, é a porta pela qual estados de desejos ardentes, de ansiedades pela vitória aparecem na vida dos competidores. Os competidores agonizam à espera da vitória. O agon - a competição - entrelaça-se com os estados anímicos dos competidores. Enquanto jogam, estes são capturados pelo jogo: seus corpos agonizam. Eles jogam com o próprio sentir, com o tempo da vitória e da derrota, com a espera pelo fim do jogo. Os jogadores embarcam numa viagem que parece levá-los para além da simples pretensão de vitória, ou do medo da derrota: agonizam. Eis um fato que não nos pode fugir ao olhar: a agonia do jogo.

Etimologicamente agonia descende de agon, da competição. O verbete agonia do Novo Dicionário Aurélio da Língua Portuguesa reza:

Agonia. [Do Gr. Agonia, 'luta' (contra a morte), pelo lat. agonia.] S.f. 1. Med. Conjunto de fenômenos mórbidos que aparecem na fase final de doenças agudas ou crônicas e anunciam a morte; ânsia de morte. 2. Espaço de tempo que dura a agonia (1). 3. Estado de moribundo; agoniação. 4. Sofrimento, amargura, dor. 5. Angústia, ansiedade, aflição: "Na agonia de tantos pesadelos / Uma dor bruta puxa-me os cabelos." (Augusto dos Anjos, Eu, p.111.) 6. Desejo ardente; ansiedade, ânsia. 7. Decadência que precede o fim: $A$

es decir, como una lucha en que la igualdad de oportunidades se crea artificialmente para que los antagonistas se enfrenten en condiciones ideales, con posibilidad de dar un valor preciso e indiscutible al triunfo del vencedor. Por tanto, siempre se trata de una rivalidad en torno de una sola cualidad (rapidez, resistencia, vigor, memoria, habilidad, ingenio, etc), que se ejerce dentro de limites definidos y sin ninguna ayuda exterior, de tal suerte que el ganador aparezca como el mejor en cierta categoria de proezas. Esa es la regla de las competencias deportivas y la razón de ser de sus multiples subdivisiones, ya opongan a dos individuos o a dos equipos (polo, tenis, futbol, box, esgrima, etc), ya se disputen entre un número indeterminado de concursantes (carreras de toda especie, competencias de tiro, de golf, de atletismo, etc.). A la misma clase pertencen además los juegos en que los adversarios disponen al principio de elementos exactamente del mismo valor y en el mismo número. El juego de damas, el ajedrez, el billar, son ejemplos perfectos. La búsqueda de la igualdade de oportunidades al principiar constituye de manera tan manifiesta el principio esencial de la rivalidad que se la restablece por medio de una ventaja entre dos jugadores de fuerzas diferentes, es decir, que dentro de la igualdad de oportunidades establecida en un principio, se prepara una desigualdade secundaria, proporcional a la fuerza relativa supuesta en los participantes. Es significativo que esse uso exista tanto para el agon de carátcter muscular (los encuentros deportivos) como para el agon de tipo más cerebral (las partidas de ajedrez, por ejemplo, en las que se da al jugador más débil la ventaja de un peón, de un caballo o de una torre). 
civilização romana entrava em agonia. 8. Termo, fim, ocaso: Vivia o grande escritor a agonia de sua glória; "Transmonta mesma hora triste, / À agonia do herói e à agonia da tarde." (Olavo Bilac, Poesias, p. 266.) 9. Pop. Náusea, enjôo. 10. Bras. Pressa, azáfama, afobação. 11. Bras. Indecisão: chove-não-molha: Vai ficar muito tempo nessa agonia? (FERREIRA, 1997, p. 63)

$\mathrm{Na}$ agonia, portanto, está em jogo como que a náusea da existência em vias de falência, em vias de inexistência. O agonístico marca o jogo da vida e da morte, marca o passo além da certeza consciente, o limiar indecidível entre a vida e a morte; entre a morte em vida e a vida que se dá para a morte. Jogar é agonizar na incerteza da existência. Tanto por isso que o tempo do jogo é diverso do chronos da existência cotidiana; é armado sempre em tempo-outro, tempo não de existências certas, nem de essências imortais (uma eternidade além-tempo), mas tempo-do-jogo, tempo da incerteza do tempo: nem histórico, nem eterno.

É num tempo de incertezas, apenas um breve interstício entre guerras, que Miguel de Unamuno agoniza em Paris. Escreve A Agonia do Cristianismo aí, na capital francesa, porém sofrendo (agonizando) pela distância da terra natal, agonizando a perda da Espanha. Quando, no domingo 30 de novembro de 1924 vai à igreja de Santo Estêvão, na rua Georges Bizet, escuta a sentença grega, provavelmente quando da ostentação da hóstia recém consagrada (recém transubstancializada: pão que se torna carne, vinho que se torna sangue; eis o corpo do cristo; eis a plenitude divina na ínfima parcela de farinha e água, na forma do mais ambíguo sinal da fraqueza humana, o vinho, que é ao mesmo tempo fonte de perdição e salvação): "Eu sou o caminho, a verdade e a vida." Unamuno põe-se imaginar

se o caminho e a vida são a mesma coisa que a verdade, se não haverá contradição entre a verdade e a vida, se a verdade não é a vida que mata e nos mantém vivos em engano. E isso me fez pensar na agonia do cristianismo, na agonia do cristianismo em si mesmo e em cada um de nós. Ainda, dá-se o cristianismo fora de cada um de nós? E aqui reside a tragédia. Porque a verdade é algo coletivo, social, até civil; verdadeiro é aquilo em que convimos e com que nos entendemos. E o cristianismo é algo individual e incomunicável. E eis aqui porque agoniza em cada um de nós. Agonia quer dizer luta. Agoniza quem vive lutando, lutando contra a vida mesma. E contra a morte. É a jaculatória de Santa Teresa de Jesus: "Morro porque não morro." (UNAMUNO, 1950, pp. 15-16)

\footnotetext{
3 "si el camino y la vida son la misma cosa que la verdad, si no habrá contradicción entre la verdad y la vida, si la verdad no es que mata y la vida nos mantiene en el engaño. Y esto me
} 
O cristão deve dizer ecce christianus, deve dizer sua agonia, deve saber que sua luta é sempre luta contra a vida $e$ contra a morte; é luta contra o que há de mais externo e ao mesmo tempo contra o que há de mais interno; contra si e contra o outro; é jogo de vida e morte; é a morte antecipada em vida e a vida que se lança na morte.

Deve mostrar sua alma cristã, sua alma de cristão, o que em sua luta, em sua agonia do cristianismo se fez. E o fim da vida é fazerse uma alma, uma alma imortal. Uma alma que é a própria obra. Porque ao morrer se deixa um esqueleto à terra, uma alma, uma obra à história. Isso quando se viveu, isto é, quando se lutou com a vida que passa pela vida que resta. E a vida, o que é a vida? Mais trágico ainda, o que é a verdade? Porque se a verdade não se define porque é ela a que define, a definidora, tampouco se define a vida (IDEM. pp. 16-17). ${ }^{4}$

A vida é indefinível, a vida é luta: luta contra a própria vida, luta contra a definidora da vida, luta contra aquilo que à vida faz par dialético, contra a morte. Jogo de vida e morte, dialética sem síntese, dialética em suspensão.

No início do seu ensaio Experiência e Pobreza, Walter Benjamin (como Unamuno, também ele escreve em meio à agonia das duas grandes guerras) nos lembra de uma fábula que trata das questões da passagem da vida à morte, isto é, uma fábula sobre o leito de morte no qual a agonia inexoravelmente se dá:

Nos nossos manuais de leitura figurava a fábula do velho homem que sobre seu leito de morte convenceu seus filhos de que um tesouro escondia-se na sua vinha. Eles já começaram a procurar. Os filhos cavam, mas nenhum traço do tesouro. Quando chega o outono, entretanto, a vinha produz como nenhuma outra em todo o país. Eles compreendem então que seu pai quis lhes legar o fruto de

hizo pensar en la agonía del cristianismo, en la agonía del cristianismo en si mismo y en cada uno de nosotros. Aunque se da acaso el cristianismo fuera de cada uno de nosostros? Y aqui estriba la tragedia. Porque la verdad es algo colectivo, social, hasta civil; verdadero es aquello en que convenimos y con que nos entendemos. Y el cristianismo es algo individual $e$ incomunicable. $Y$ he aqui por qué agoniza en cada uno de nosotros. Agonía quiere decir lucha. Agoniza el que vive luchando, luchando contra a vida misma. Y contra la muerte. Es la jaculatoria de Santa Teresa de Jesús: "Muero porque no muero."

4 "Debe mostrar su alma cristiana, su alma de cristiano, lo que en su lucha, en su agonía del cristianismo se ha hecho. Y el fin de la vida es hacerse un alma, un alma immortal. Un alma que es la propia obra. Porque al morrir se deja un esqueleto a la tierra, un alma, una obra a la historia. Esto cuando se ha vivido, es decir, cuando se ha luchado con la vida que pasa por la vida que se queda. Y la vida, qué es la vida? Más tágico aún, qué es la verdad? Porque si la verdad no se define porque es ella la que define, la definidora, tampoco se define la vida." 
sua experiência: a verdadeira riqueza não está no ouro, mas no trabalho (BENJAMIN, 2005, p. 364). ${ }^{5}$

Ainda que interpretações moralizantes possam ser feitas - como a valorização do trabalho, a lição de moral aplicada pelo pai (aliás, mais do que uma lição de moral, o que o pai faz é pregar uma peça nos filhos) - o que aqui importa salientar, além do conteúdo da mensagem, é o modo como a experiência foi transmitida: na agonia, no limiar entre a vida e a morte. A experiência é a transmissibilidade de si própria no jogo agônico de vida e morte. Ex periri, expor-se ao perigo, é expor-se ao perigo de morte, é agonizar.

Ora é precisamente ao morrer que o indivíduo transmite, em primeira mão, não apenas os seus conhecimentos mas, sobretudo, a experiência de sua vida - isto é a matéria com que se constroem as histórias. Assim como no interior do indivíduo, agonizante, desfila uma seqüência de imagens - quadros de situações por ele vividas, sem se ter dado conta - também o inesquecível aflora, de repente, na sua fisionomia e no seu olhar, conferindo autoridade a tudo o que lhe dizia respeito. Na hora da morte, até o maior pobre-diabo possui essa autoridade perante os vivos que o rodeiam. Esta autoridade está presente na origem da narrativa (BENJAMIN, 1992, p. 40).

Assim, como nessa parte do ensaio sobre o Narrador, Benjamin estabelece, de certo modo, uma maneira de ler e entender a experiência (termo que em alemão se diz Erfahrung - literalmente percorrer, atravessar uma região durante uma viagem) para além daquilo que a seus olhos (o de um filósofo que assiste uma transmutação da existência cultural de seu meio: a guerra, a modernidade, a técnica) se dava a ver: a experiência, na era moderna, não era senão Erlebnis, isto é, vivência (GAGNEBIN, 2004, pp. 58-59) - a inefável particularidade (que, talvez, é aquilo para o qual Unamuno parece nos chamar a atenção).

$\mathrm{Na}$ modernidade a agonia daquele que quer legar uma experiência parece não mais ser possível senão na sua forma extrema: a transmissão de um intransmissível, a experiência de um inexperienciável. Uma experiência da morte em vida. Confrontarnos com isso é, em certa medida, um modo de se colocar no jogo da agonia e também

\footnotetext{
5 "Dans nos manuels de lecture figurait la fable du vieil homme qui sur son lit de mort fait croire à ses enfants qu'un tresor est cachê dans sa vigne. Ils n'ont qu'à chercher. Les enfants creusent, mais nulle trace de tresor. Quand vient l'automne, cependant, la vigne donne comme aucune autre dans tout le pays. Ils comprennent alors que leur pêre a voulu leur léguer le fruit de son expérience: la vraie richesse n'est pas dans l'or, mais dans le travail."
} 
de tentar entender a condição humana na modernidade. É a busca dessa compreensão que estava também nos questionamentos mitológicos de Furio Jesi.

A insistência com a qual em diversos de seus escritos o mitólogo italiano citava um verso dos Sonetos a Orfeu de Rilke ("Wer sich als Quelle ergießt, den erkennt die Erkennung" - em português: "Quem se derrama como fonte, é conhecido do conhecimento") pode nos dar as indicações da busca por um conhecimento do estágio liminar entre vida e morte.

A máquina mitológica de Jesi - operação estratégico-metodológica por ele concebida - é, de certo modo, o meio de compor antagonismos de maneira tensiva e bipolar, mais do que opositiva e dicotômica: vida e morte, consciente e inconsciente, humano e inumano podem ser os elementos da máquina que, para funcionar, tem um núcleo vazio - o vazio de significações - a partir do qual aqueles elementos ganham sentido. Num de seus famosos estudos sobre Károly Kerényi, Jesi analisa o que chama de religio mortis - que para ele era evidente nos "pensamentos secretos" de Ezra Pound. Aqui ele retoma a citação de Rilke justamente para falar sobre de que modo essa religião da morte se daria como um tomar parte na convicção de que com a morte o ser humano entretém um comportamento "através do qual a morte acederia à 'verdade superior' de ser 'algo e ao mesmo tempo nada'" (JESI, 2001, p. 29). ${ }^{6}$ Jesi procura no hiato de sua máquina mitológica um conhecimento da morte. Diz ele que

poesia e mitologia (ou, se quisermos, essência da poesia e da mitologia) sobrevivem na cultura moderna também na medida em que a sua sobrevivência é circunscrita, defesa e alimentada por um "algo e ao mesmo tempo nada" que vale seja como suas definições, seja como horizonte próximo do comportamento com a morte. À sobrevivência da poesia e da mitologia neste presente, e não somente neste, já que não parece ser a primeira vez que isto acontece, parece apropriado, mesmo se talvez não de modo exclusivo, um terreno de cultura que se conserva nutritivo e quente, não obstante os gelos e as esterilizações do agora, graças às qualidades da morte, que são múltiplas e de vários modos de eficácia $(I D E M){ }^{7}$

\footnotetext{
6 "attraverso il quale la morte accederebbe alla 'verità superiore' d'essere 'qualcosa e insieme nulla'."

7 "Poesia e mitologia (o, se vogliamo, essenza della poesia e della mitologia) sopravvivono nella cultura moderna anche nella misura in cui la loro sopravvivenza è circoscritta, difesa e alimentata da un 'qualcosa e insieme nulla' che vale sia come loro definizione, sia come orizzonte vicino del comportamento con la morte. Alla sopravvivenza della poesia e della mitologia in questo presente, e non solo in questo poiché non pare essere la prima volta che ciò accade, sembra appropriato, anche se forse non in modo exclusivo, un terreno di coltura che si conserva nutritizio e caldo nonostante i geli e le sterilizzazioni dell'ora, grazie alle qualità della morte, che sono molteplici e in vario modo efficaci."
} 
Buscar um conhecimento da morte, procurar um conhecimento além do qual só pode estar um derramar-se como fonte (isto é, saber que conhecimento só pode se dar quando quem pretende conhecer concebe seu próprio conhecer como já imerso num conhecimento que lhe ultrapassa e que, portanto, sempre deixa um resto incompreensível), é contrapor à morte - enrijecida num 'mito da morte', que se traduz aqui no comportamento humano com a morte - um fluir de vida humana, esta que, porém, só pode estar circunscrita por este "algo e ao mesmo tempo nada" que é a morte.

Desse modo, este "algo e ao mesmo tempo nada" que se funda como o núcleo escondido de uma máquina (mitológica, poetológica ou antropológica) é o que permite a essa seu funcionamento. Somente com um resíduo internalizado - que, porém, é absolutamente vazio de significações, isto é, tal como dizia Lévi-Strauss, que excede todo significado - é que o mecanismo de formulação de uma propriedade humana pode funcionar. A morte, o que há de mais exterior, é, dessa maneira, colocada como elemento intrínseco ao processo de conhecimento levado às últimas consequências: um conhecimento do impossível.

Talvez seja essa impossibilidade de acesso ao jogo da vida, ao jogo da própria vida (ao lance de morte que se emaranha na vida) que Murilo Mendes, ao delinear seu Mapa (ao delinear a impossibilidade de seu mapa, a impossibilidade de cartografar-se), em meados da década de vinte, dizia:

Danço. Rio e choro, estou aqui, estou ali, desarticulado, gosto de todos, não gosto de ninguém, batalho com os espíritos do [ar, alguém da terra me faz sinais, não sei mais o que é o bem nem o mal.

Minha cabeça voou acima da baía, estou suspenso, angustiado, no [éter, tonto de vidas, de cheiros, de movimentos, de pensamentos, não acredito em nenhuma técnica.

Estou com os meus antepassados, me balanço em arenas [espanholas, é por isso que saio às vezes pra rua combatendo personagens imaginários, depois estou com os meus tios doidos, às gargalhadas, na fazenda do interior, olhando os girassóis do jardim. Estou no outro lado do mundo, daqui a cem anos, levantando [populações...

Me desespero porque não posso estar presente a todos os atos da vida. 
Onde esconder minha cara? O mundo samba na minha cabeça.

Triângulos, estrelas, noite, mulheres andando,

presságios brotando no ar, diversos pesos e movimentos me

[chamam a atenção,

o mundo vai mudar a cara,

a morte revelará o sentido verdadeiro das coisas (MENDES, 1994c, p. 117).

O devaneio do poeta em vida; cartografar a própria perdição, sondar o insondável, vasculhar jogos imaginários, dançar na agonia da vida. Eis o jogo de vida em que a experiência de uma vida só se dá na agonia da morte. Não a vivência privatística de uma alma que pena e chora, mas a partilha da vida num mundo que pisoteia e esmaga, que aperta e impinge apenas uma dor agoniada. A você, poeta, só resta uma verdade: a morte.

A vida é luta, e a solidariedade para a vida é luta e se faz na luta. Não me cansarei de repetir que o que mais nos une, os homens uns aos outros, são as nossas discórdias. E o que mais une cada um a si mesmo, o que faz a unidade íntima de nossa vida, são nossas discórdias íntimas, as contradições interiores de nossas discórdias. Alguém só se coloca a par de si mesmo, como Dom Quixote, para morrer. E se isso é a vida física ou corporal, a vida psíquica ou espiritual é, por sua vez, uma luta contra o eterno esquecimento. E contra a história. Porque a história, que é o pensamento de Deus na terra dos homens, carece de última finalidade humana, caminha para o esquecimento, para a inconsciência. E todo o esforço do homem é dar finalidade humana para a história, finalidade sobrehumana, diria Nietzsche, que foi o grande sonhador do absurdo: o cristianismo social (UNAMUNO, 1950, pp. 17-18). ${ }^{8}$

As duas lutas das duas vidas esboçadas por Unamuno - diga-se, um dos mestres de Murilo Mendes - são sinóticas. A morte física e a morte espiritual; a morte do corpo e o esquecimento. Somos puro combate: combatemos - agonizamos - o

\footnotetext{
8 "La vida es lucha, y la solidaridad para la vida es lucha y se hace en la lucha. No me cansaré de repetir que lo que más nos une a los hombres unos con otros son nuestras discordias. Y lo que más le une a cada uno consigo mismo, lo que hace la unidad intima de nuestra vida, son nuestras discordias intimas, las contradiciones interiores de nuestras discordias. Solo se pone uno en par consigo mismo, como Don Quijote, para morir. Y si esto es la vida física o corporal, la vida psíquica o espiritual es, a su vez, una lucha contra el eterno olvido. Y contra la história. Porque la historia, que es el pensamiento de Dios en La tierra de los hombres, carese de ultima finalidad humana, camina al olvido, a la inconsciência. Y todo el esfuerzo del hombre es dar finalidad humana a la historia, finalidade sobrehumana que diria Nietzsche, que fué el gran soñador del absurdo: el cristianismo social."
} 
nada (aquele resíduo interno da máquina homem para o qual Jesi (JESI, 2001, pp. 2931) insistentemente nos chama a atenção).

Talvez também seja por isso que o jogo da vida compele o poeta ao trabalho literário (como a bela imagem blanchotiana da mão que pode interromper a escritura, enquanto a outra, a que nunca solta o lápis, pensando estar no domínio, não percebe a fragilidade do seu ato, o caráter tênue da escrita (BLANCHOT, 1987, p. 15-16) ${ }^{9}$ ); talvez seja por isso que o poeta - Murilo, agora, em 1970, quase cinquenta anos depois de tentar mapear-se - se micro-defina (se autorretrate) como que compelido pela impossibilidade de experimentar a própria vida senão nas antessalas agonizantes da morte: "Sinto-me compelido ao trabalho literário: pelo desejo de suprir as lacunas da vida real; pela minha teimosia em rejeitar as 'avances' da morte (tolice: como se ela usasse o verbo adiar)" (MENDES, 1994b, p. 45).

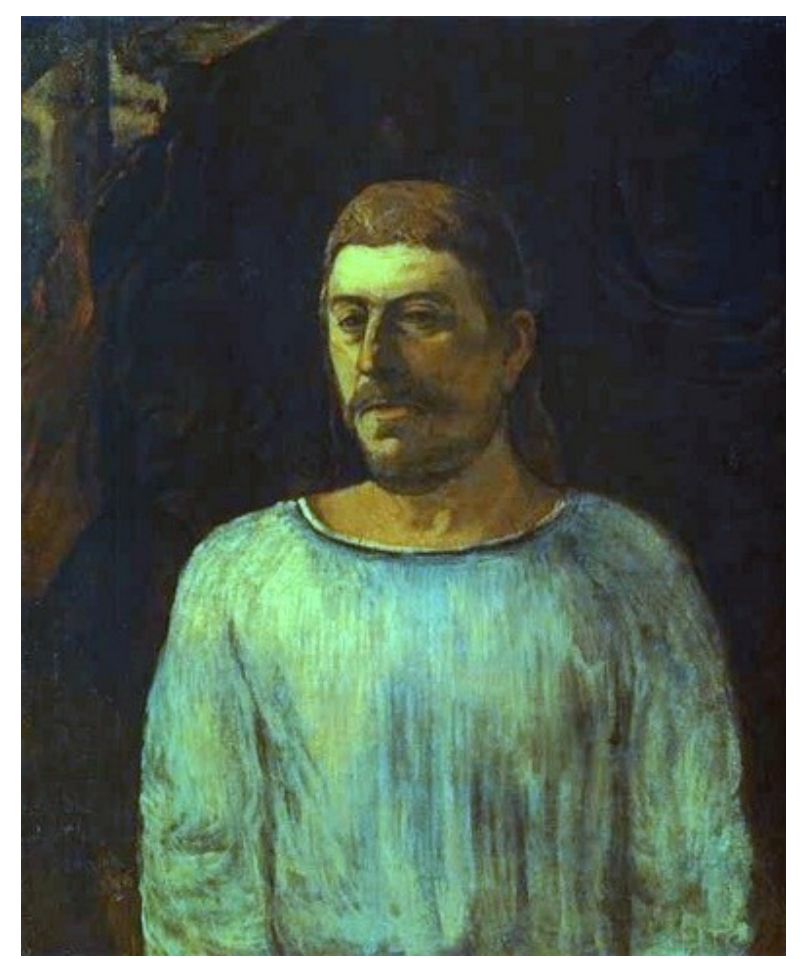

Fig. 01. Paul Gauguin. Autorretrato (perto do Gólgota), 1896. MASP

\footnotetext{
9 "O domínio do escritor não está na mão que escreve, essa mão "doente" que nunca solta o lápis, que não pode soltá-lo, pois o que segura, não o segura realmente, o que segura pertence à sombra e ela própria é uma sombra. O domínio é sempre obra da outra mão, daquela que não escreve, capaz de intervir no momento adequado, de apoderar-se do lápis e de o afastar. Portanto, o domínio consiste no poder de parar de escrever, de interromper o que se escreve..."
} 
A agonia vem e pega a vida em despreparo; ou melhor, a vida deixa-se capturar pela agonia, numa espécie de tramado indiscernível entre a vida e a morte. $\mathrm{O}$ enigma da existência, do pânico na existência, deságua nos suspiros pela morte, esta, doce enigma:

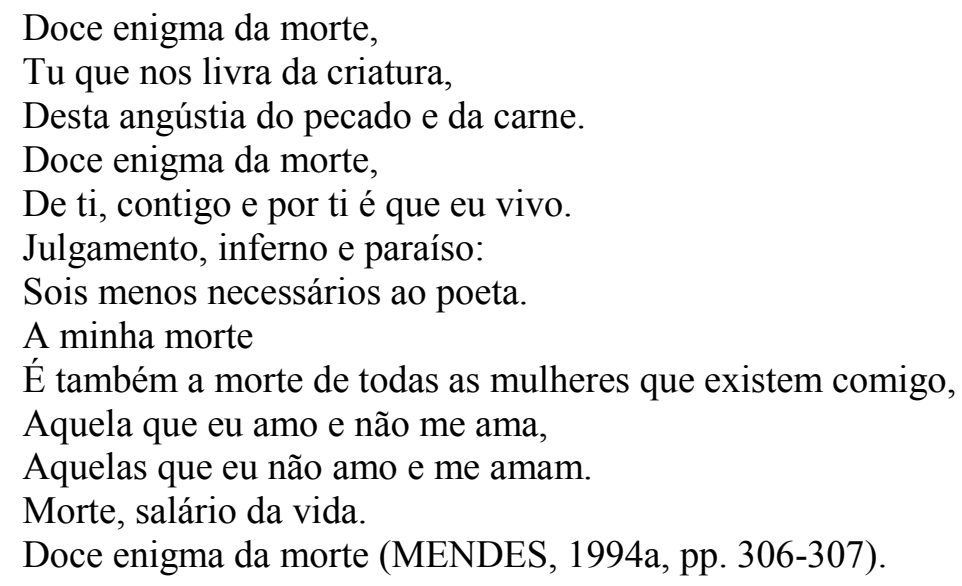

Se há um lugar em que o enigma da morte se mostra com toda sua pujança é na cruz do Cristo. O calvário, o Gólgota, é o lugar de anseio - de agonia - necessário ao Cristo para da salvação do homem. É onde acontece a plena intervenção divina na história (no jogo) da humanidade. É aí, no altar no qual a imolação do cordeiro de deus acontece, que o homem vê a imagem do enigma da morte: o salário da vida.

Paul Gauguin, no limiar da depressão - após a morte de uma de suas filhas e do começo de suas crises sifilíticas -, aí também se autorretrata: perto do Gólgota. Os clamores de agonia do cristo ressoam na escuridão da tela: "Meu Deus, Meu Deus, por que me abandonaste?" (Mt. 27;45). Gauguin está abandonado no jogo da vida. Agoniza a morte intentada (há alguns meses o suicídio tinha sido uma busca de saída - saída do jogo de vida e morte - malfadada) e que não chega: chega, porém, como vida agoniada. O olhar perdido, o negrume da tela, as aparentes colunas (seriam cruzes?) tombadas no canto superior esquerdo da tela, contrastando com o branco rasgado da roupa do condenado. Estava na polinésia francesa, no paraíso terrestre. Porém, é aqui que o pintor encontra seu inferno. Jogo de opostos no qual resta uma luta, uma agonia, para o artista.

A luta intrínseca na vida é a agonia de uma experiência na qual o perigo da existência é algo e ao mesmo tempo nada; é a tarefa do poeta (do artista e, porque não, de todo homem) lidar com esse vazio o qual, como o contraponto entre a escuridão e a luz (do autorretrato de Gauguin, do mapa muriliano, das aspirações de 
Unamuno), não é o resultado vitorioso ou derrotista num jogo, mas a suspensão irremediável dos resultados e a aceitação do titubear diante das indefinições e incertezas da vida e da morte: Murilo teimando em rejeitar o adiantamento da morte; Gauguin teimando adiantar-se à morte; Unamuno agonizando pela paz na guerra ou pela guerra na paz da vida do cristão (UNAMUNO, 1950, p. 22) ${ }^{10}$; Benjamin pensando a experiência na agonia. Os tabuleiros das vidas são as apostas agonísticas e agoniadas de um jogo da vida que, porém, é sempre dado na dialética em suspensão de uma morte/vida intermitente e de uma vida/morte sempre imanente...

\section{REFERÊNCIAS}

BENJAMIN, Walter. Expérience et pauvreté. In.: Oeuvres II. Paris: Gallimard, 2005. . O Narrador. In.: Sobre Arte, Técnica, Linguagem e Política. Lisboa: Relógio d’Água, 1992.

BLANCHOT, Maurice. O espaço literário. Rio de Janeiro: Rocco, 1987.

CAILlOIS, Roger. Los juegos y los hombres. La máscara y el vértigo. México: Fondo de Cultura Económica, 1986.

FERREIRA, Aurélio Buarque de Holanda. Novo dicionário da língua portuguesa. Rio de Janeiro: Ed. Nova Fronteira, 1997. $2^{\text {a }}$ Ed. Revista e aumentada. $36^{\mathrm{a}}$ impressão.

GAGNEBIN, Jeanne Marie. História e narração em Walter Benjamin. São Paulo: Perspectiva, 2004.

HUIZINGA, Johan. Homo Ludens. O jogo como elemento da cultura. São Paulo: Perspectiva, 2007.

JESI, Furio. Materiali Mitologici. Mito e antropologia nella cultura mitteleuropea. Torino: Einaudi, 2001.

LÉVI-STRAUSS, Claude. Introdução à obra de Marcel Mauss. In. MAUSS, Marcel. Sociologia e Antropologia. São Paulo: EPU/EDUSP, 1974. Tradução: Lamberto Puccinelli.

MENDES, Murilo. A poesia em pânico. In.: Poesia Completa e Prosa. Org. Luciana Stegagno Picchio. Rio de Janeiro: Editora Nova Aguilar, 1994a.

\footnotetext{
10 "Alguien podrá decir que la paz es la vida - o la muerte - y que la guerra es la muerte - o la paz-, pues es casi indiferente asimilarlas a una o a otra respectivamente, y que la paz en la guerra - o la guerra en la paz - es la vida en la muerte, la vida de la muerte y la muerte en la vida, que es la agonía."
} 
. Murilo Mendes por Murilo Mendes. In.: Poesia Completa e Prosa. Org. Luciana Stegagno Picchio. Rio de Janeiro: Editora Nova Aguilar, 1994b.

Poemas. In: Poesia completa e prosa. Org. Luciana Stegagno Picchio. Rio de Janeiro: Editora Nova Aguilar, 1994c.

UNAMUNO, Miguel de. La agonía del cristianismo. Buenos Aires-México: EspasaCalpe Argentina S.A., 1950. 